\title{
Preparation of chitosan gel
}

\author{
Y. Moussaoui $^{1, \mathrm{a}}$, N. Mnasri ${ }^{2}$, E. Elaloui ${ }^{2}$, R. Ben Salem ${ }^{1}$, S. Lagerge ${ }^{3}$, L. C. de Menorval ${ }^{3}$ \\ ${ }^{1}$ Physical Organic Chemistry Laboratory, Science Faculty of Sfax, 3018, Sfax, Sfax University, \\ Tunisia. \\ ${ }^{2}$ Material, Environment and Energy Laboratory, Science Faculty of Gafsa, 2112, Gafsa, Gafsa \\ University, Tunisia. \\ ${ }^{3}$ Laboratory of Aggregates, Interfaces and Materials for Energy, Charles Gerhardt Institute, \\ Montpellier 2 University, France.
}

\begin{abstract}
Aerogel conditioning of the chitosan makes it possible to prepare porous solids of significant specific surface. The increase in the chitosan concentration or the degree of acetylation decreases the specific surface of the synthesized chitosan gel. Whereas drying with supercritical $\mathrm{CO}_{2}$ more effectively makes it possible to preserve the volume of the spheres of gel and to have a more significant specific surface in comparison with evaporative drying.
\end{abstract}

\section{Introduction}

Chitosan is natural biodegradable polymer produced by deacetylation of chitin [1-3]. It is a $\beta-(1,4)-$ linked polysaccharide of D-glucosamine. The discovery of chitosan date of the 18th century, but it is only in the years 1970 that this product aroused a real interest [4-9]. Chitosan, a $\beta-(1,4)$-linked polysaccharide of D-glucosamine, is a deacetylated form of chitin [10,11]. Chitosan is a non toxic, biodegradable and biocompatible [12-14] natural polymer, and the second most abundant natural polymer in the world [15]. It is derived from naturally occurring sources, which is the exoskeleton of insects, crustacean such as crabs, shrinps, prawns, lobsters and cell walls of some fungi such as aspergillus and mucor [16-21].

Currently, it is known that chitin and chitosan are renewable sources which one can find in abundance in nature. This fact attracted more interest for the durable development. However, chitosan is used in many applications [22,23]. It is known for its biocompatibility allowing its use in various medical applications such as implantation [24], injection [25], antacid and antiulcer activities [26], potential carrier for drugs [27], biomedical applications [28]. Chitosan also promotes wound healing [29] and has antibacterial action [30,31]. It is also acts as flocculent for the treatment of wastewater [32-34]. Chitosan is appeared as an amorphous solid. It is one of the rose natural polyelectrolytic cation existing in nature. It differs from chitin only by the amino groups. This difference has a significant effect on the properties of this material. Indeed, the chitosan is soluble in the diluted acids whereas chitin dissolves with difficulty in solvents. The richness of the chitosan in particular its degree of desacetylation at the origin of its potential, added with the biological

\footnotetext{
${ }^{a}$ e-mail : y.moussaoui2@gmx.fr
}

This is an Open Access article distributed under the terms of the Creative Commons Attribution License 2.0, which permits unrestricted use, distribution, and reproduction in any medium, provided the original work is properly cited. 
properties, make of it a polymer particularly interesting for a multitude of applications. However, the gel formation is one of the most appreciated for the chitosan applications $[35,36]$.

\section{Experimental}

\subsection{Gel preparation}

The chitosan is dissolved in an acetic acid solution $(\mathrm{pH}=4)$. The prepared solution is injected drop by drop using a syringe in a gelling solution (solution of sodium hydroxide $3 \mathrm{M}$ or sodium dodecylsulphate solution $50 \mathrm{mM})$. The obtained solution is maintained for 6 hours at room temperature $\left(25^{\circ} \mathrm{C}\right)$. Obtained hydrogel (in the form of balls) is filtered, then immersed in baths containing ethanol/water solutions of which the proportions are: 1/9, 3/7, 5/5, 9/1,1/0. One obtains finally an alcogel, which thereafter undergoes an evaporative drying or a drying with supercritical $\mathrm{CO}_{2}$.

\subsection{Evaporative drying}

Evaporative drying is carried out in a vacuum drying (reduced pressure) at ambient temperature during 12 hours.

\subsection{Drying with supercritical $\mathrm{CO}_{2}$}

The alcogel is introduced into an autoclave in the presence of $\mathrm{CO}_{2}$ and compressed until the field of stability of liquid $\mathrm{CO}_{2}\left(50\right.$ bars, $\left.4^{\circ} \mathrm{C}\right)$. Then, one increases the temperature until $31,05^{\circ} \mathrm{C}$, the pressure goes up to 73,8 bars, which allows a change of state of $\mathrm{CO}_{2}$ from the liquid state to the supercritical state. Finally, supercritical $\mathrm{CO}_{2}$ is evacuated before cooling to recover the dry solid.

\subsection{Thermal analysis}

The thermal transformations of the gel were followed by differential thermoanalysis (DTA) and thermogravimetric analysis (TGA) using a thermobalance and alumina as reference. A few milligrams of dried gel placed in side a microbalance were pyrolyzed under nitrogen from ambient temperature to $800^{\circ} \mathrm{C}$ with a constant heating rate of $10^{\circ} \mathrm{C} / \mathrm{min}$.

\subsection{Adsorption-desorption isotherms}

Measurements are performed using a Micrometrics equipment ASAP 2020. We use $\mathrm{N}_{2}$ at the temperature of $77 \mathrm{~K}$. Before adsorption, all samples were degassed in vacuum at $250^{\circ} \mathrm{C}$ during 15 hours. This technique of gas adsorption gives access to the specific surface $\mathrm{S}_{\mathrm{BET}}\left(\mathrm{m}^{2} \cdot \mathrm{g}^{-1}\right)$. Determination of specific area was carried out taking $16.2 \AA^{2}$ as cross sectional area of $\mathrm{N}_{2}$.

\subsection{Scanning electronic microscopy}

The images of SEM were obtained with a Hitachi S-2600N apparatus, using a detector of secondary electrons.

\section{Results and discussion}

The xerogel and aerogel are synthesized as shown in figure 1. 


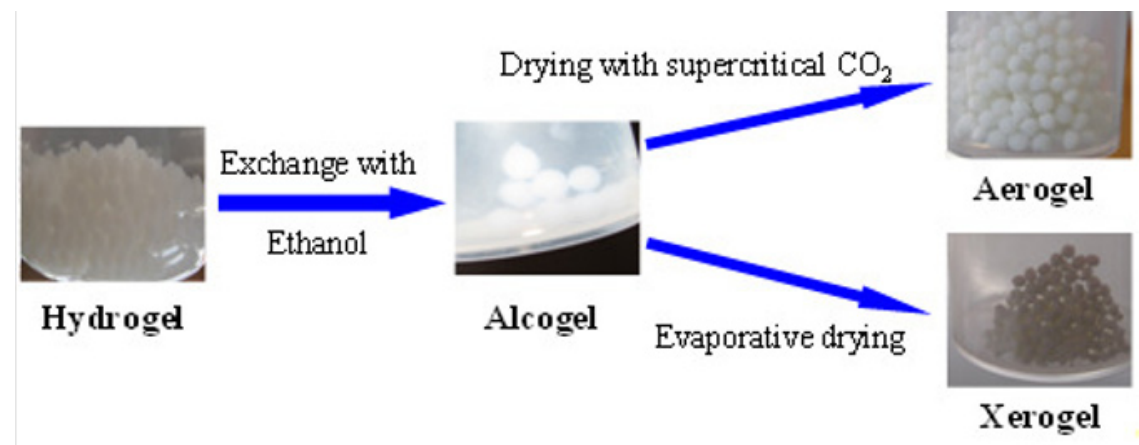

Fig. 1. Synthesis of chitosan gel (Aarogel and Xerogel)

The aerogel prepared by drying with supercritical $\mathrm{CO}_{2}$, preserves the dispersion of the hydrocolloids from which they result. Thus, $\mathrm{CO}_{2}$ supercritical drying makes it possible more effectively to preserve the volume of the spheres of gel in comparison with the evaporative drying.

\subsection{Thermal analyses:}

The thermal analyses were performed on powders obtained from chitosan gels. Figure 2 reported the curves for the different samples.

The DTA data showed for the gels obtained from chitosan (batch-112) gelled by sodium hydroxide a weight losses in the temperature range $100-200^{\circ} \mathrm{C}$ "Fig2. a,b,c and d". Thus, these gels are stable in this temperature range. The difference between the aerogel (a) and the xerogel (b) appears on the level of the pace of DTA. Indeed the aerogel presents a more intense peak at $640^{\circ} \mathrm{C}$ than that of the xerogel. This indicates the complete burn of the aerogel. For the xerogel resulting from the chitosan (batch-111) one notices the absence of the weight loss in the temperature range $100-200^{\circ} \mathrm{C}$ as chown for the chitosan (batch-112). This difference is due to the degree of acetylation.

The xerogel gelled by SDS (e), takes a form of TGA similar to the xerogel gelled by sodium hydroxide (b). The only difference is at the DTA spectra where the xerogel is completely degraded towards $500^{\circ} \mathrm{C}$. 

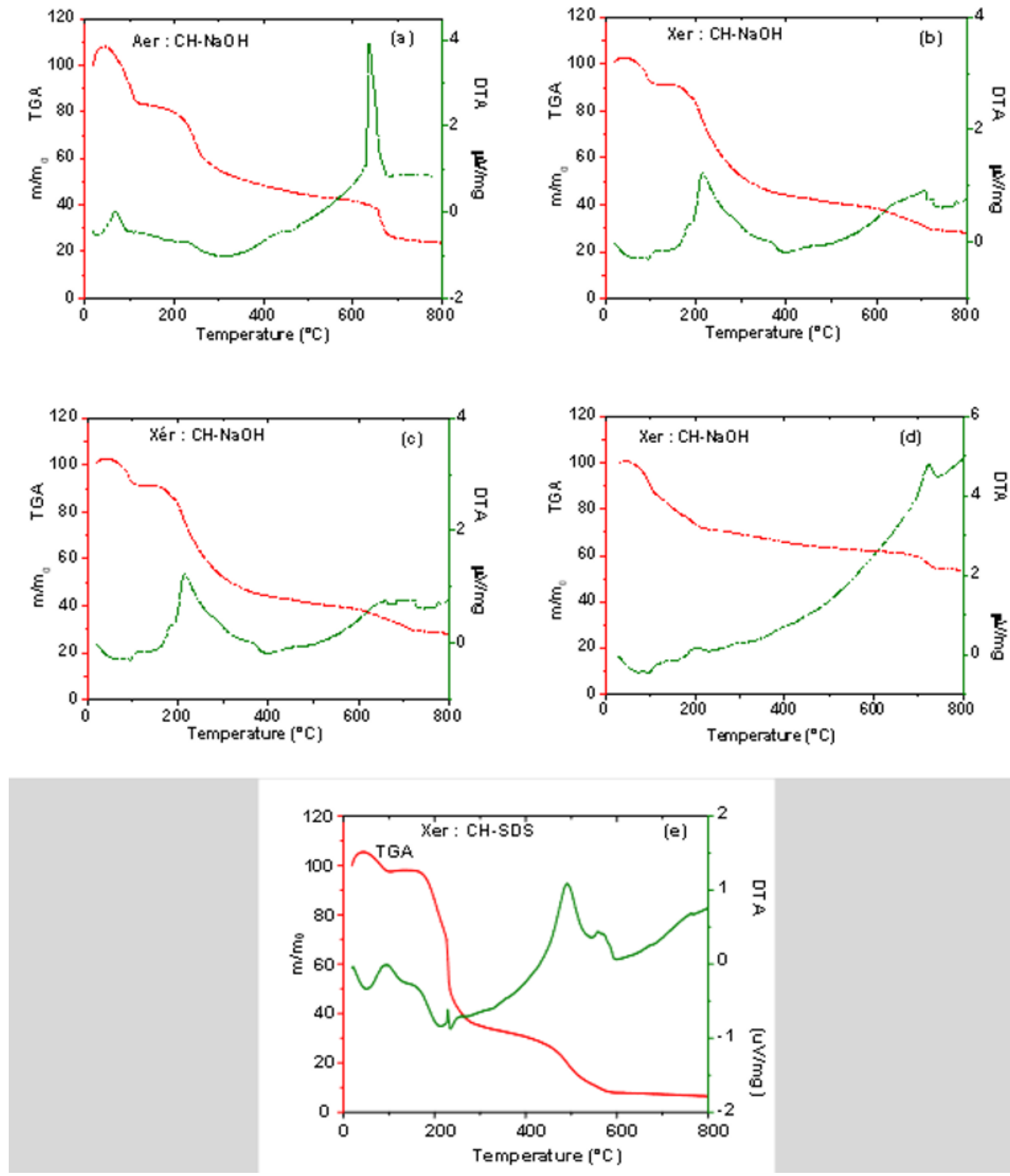

Fig. 2. DTA and ATG curves of chitosan gels:

(a): Aerogel: chitosan (batch-112) gelled by $\mathrm{NaOH}$, [chitosan] $=1,5 \%$.

(b): Xerogel: chitosan (batch-112) gelled by $\mathrm{NaOH}$, [chitosan] $=1,5 \%$.

(c): Xerogel: chitosan (batch-112) gelled by $\mathrm{NaOH}$, [chitosan] $=2,3 \%$.

(d): Xerogel: chitosan (batch-111) gelled by $\mathrm{NaOH}$, [chitosan] $=1,5 \%$

(e): Xerogel: chitosan (batch-112) gelled by SDS, [chitosan] $=1,5 \%$

\subsection{Textural analyses}

The adsorption/desorption isotherms of all the gels, shown in figure 3, belong to type II in the IUPAC classification, which are characteristics of macroporous materials. Specific surface areas, SBET, vary from $5 \mathrm{~m}^{2} \cdot \mathrm{g}^{-1}$ to $142 \mathrm{~m}^{2} \cdot \mathrm{g}^{-1}$ (table1). As shown in Fig. 3 (a), the hysteresis loop start appearing at lower relative pressures for the chitosan aerogel indicates that the overage pore size is larger compared to chitosan xerogels. The isotherm of the aerogel shows an initial walk of adsorption to low pressure, which corresponds to full-course of adsorbed nitrogen. Pore volume 
measurements by nitrogen adsorption show a pore volume of $33 \mathrm{~cm}^{3} \cdot \mathrm{g}^{-1}$ for the xerogel (b) obtained from chitisan (batch-112) (1,5\%) gelled by sodium hydroxide $3 \mathrm{M}$. The specific surface areas are respectively $142 \mathrm{~m}^{2} \cdot \mathrm{g}^{-1}$ and $82 \mathrm{~m}^{2} \cdot \mathrm{g}^{-1}$.
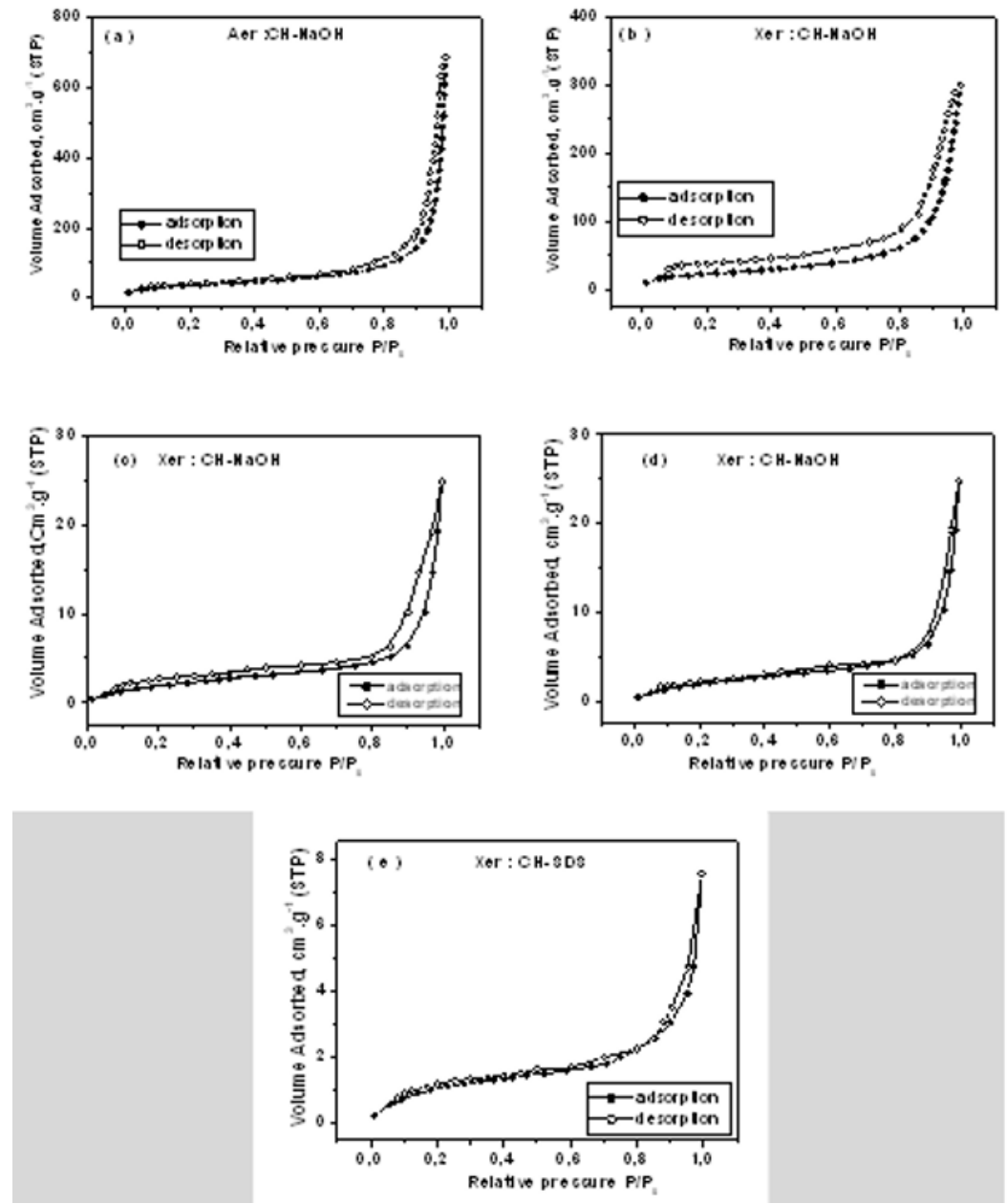

Fig. 3. Nitrogen adsorption-desorption isotherms of gels at $77 \mathrm{~K}$ :

(a): Aerogel: chitosan (batch-112) gelled by $\mathrm{NaOH}$, [chitosan] $=1,5 \%$.

(b): Xerogel: chitosan (batch-112) gelled by $\mathrm{NaOH}$, [chitosan] $=1,5 \%$.

(c): Xerogel: chitosan (batch-112) gelled by $\mathrm{NaOH}$, [chitosan] $=2,3 \%$.

(d): Xerogel: chitosan (batch-111) gelled by $\mathrm{NaOH}$, [chitosan] $=1,5 \%$

(e): Xerogel: chitosan (batch-112) gelled by SDS, [chitosan] $=1,5 \%$

This difference in specific surface between the aerogel and the xerogel is due to the process of drying. Evaporative drying undergoes a significant loss of volume, which had with the surface stress of the evaporated liquid. However, supercritical drying preserves the pore texture, by avoiding surface tensions and shrinkage due to the appearance of liquid-vapour interfaces [37].

Comparison between isotherms of xerogels "Fig 3. (b-e)" shows that adsorption on xerogel (b) is stronger than the other xerogels. This confirms the greatest specific surface of xerogel (b). However, increase in the chitosan concentration decreases the specific surface (table1) of obtained gels. In the same way, specific surface decreases when increasing the DA of chitosan [11,38-40] 
Table 1. Surface area of chitosan gels.

\begin{tabular}{|c|c|c|c|c|c|}
\hline & Aerogel (a) & Xerogel (b) & Xerogel (c) & Xerogel (d) & Xerogel (e) \\
\hline Chitosan & Batch-112 & Batch-112 & Batch-112 & Batch-111 & Batch-112 \\
\hline [Chitosan] (\%) & 1,5 & 1,5 & 2,3 & 1,5 & 1,5 \\
\hline DA of Chitosan & 2,9 & 2,9 & 2,9 & 13 & 2,9 \\
\hline Gelling solution & $\begin{array}{c}{[\mathrm{NaOH}]=} \\
3 \mathrm{M}\end{array}$ & $\begin{array}{c}{[\mathrm{NaOH}]=} \\
3 \mathrm{M}\end{array}$ & {$[\mathrm{NaOH}]=3 \mathrm{M}$} & {$[\mathrm{NaOH}]=3 \mathrm{M}$} & $\begin{array}{c}{[\mathrm{SDS}]=} \\
50 \mathrm{mM}\end{array}$ \\
\hline SBET (m2.g-1) & 142 & 82 & 10 & 9 & 5 \\
\hline
\end{tabular}

\subsection{Scanning electron microscopy analysis}

Figure 4 shows that chitosan aerogel consist of a porous structure. The aerogel present a form of scaffolds consisted on fibers or leafs disorderly distributed in layers showing its highly porous structure consisting of interconnected pores. While xerogels showed a microspheric form "Fig 4.". The presence of microfibrils in the morphologic structure of the aerogel suggests that the aerogel has characteristics, which make it a good candidate for fiber spinning [39].

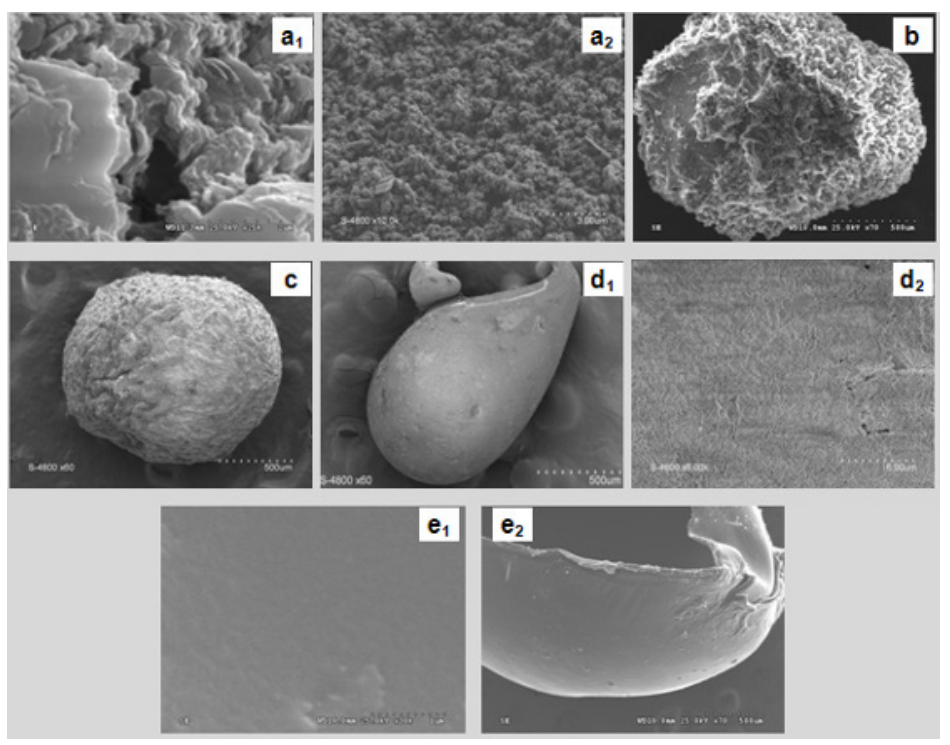

Fig. 4. SEM images of chitosan gel

$\left(\mathrm{a}_{1}\right.$ and $\left.\mathrm{a}_{2}\right)$ : Aerogel: chitosan (batch-112) gelled by $\mathrm{NaOH}$, [chitosan] $=1,5 \%$.

(b): Xerogel: chitosan (batch-112) gelled by $\mathrm{NaOH}$, [chitosan] $=1,5 \%$.

(c): Xerogel: chitosan (batch-112) gelled by $\mathrm{NaOH}$, [chitosan] $=2,3 \%$.

$\left(\mathrm{d}_{1}\right.$ and $\left.\mathrm{d}_{2}\right)$ : Xerogel: chitosan (batch-111) gelled by $\mathrm{NaOH}$, [chitosan] $=1,5 \%$.

$\left(\mathrm{e}_{1}\right.$ and $\left.\mathrm{e}_{2}\right)$ : Xerogel: chitosan (batch-112) gelled by SDS, [chitosan] $=1,5 \%$. 


\section{Conclusions}

In conclusion, we could highlight that the chitosan concentration, the degree of acetylation (DA) of the chitosan and the drying conditions of the alcogels have an influence on the final properties of the aerogel or the xerogel. The increase in the chitosan concentration or the degree of acetylation decreases the specific surface of the chitosan gel. Whereas $\mathrm{CO}_{2}$ supercritical drying preserves the dispersion of the hydrocolloids from which they result.

\section{References}

1. C. J. Brine, P.A. Sandford, J.P. Zikakis, advances in chitin and chitosan. Elsevier londres, angleterre (1992).

2. E. Curotto, F. Aros, anal. Biol. 211, 240 (1993).

3. J. P. Zikakis (ed), Chitin, Chitosan and related enzymes, Academic Press, Orlando, p. XVII (1984).

4. R. A. A. Muzzarelli, Chitin 1er edition, Pergamon Press Oxford, Angleterre (1977).

5. M.G. Muzzarelli, US Patent 3635818 (1972).

6. S. Tokuras, N. Nishi, Kagaku Seibutsu 15, 766 (1977).

7. R. A. A. Muzzarelli, Italian Patent 625-A-78 (1978).

8. K. G. Scott, US Patent 4056392 (1977).

9. R. A. A. Muzzarelli, natural chelating polymers oxford: Pergamon Press pp. 83-176 (1973).

10. T. O. Truong, R. Hausler, F. Monette, P. Niquette, Revue des Sciences de l'eau 20, 253 (2007).

11. M.N.V. Ravi Kumar, Reactive Functional polymers 46, 1 (2000).

12. S. Hirano, H. Seino, Y. Akiyama, I. Nonaka, Chitosan: a biocompatible material for oral and intravenous administration. In: Gebelein $\mathrm{CH}$, Dunn RL, editors. Progress in biomedical polymers. New York: Plenum Press; pp. 283-290 (1990).

13. R.A.A. Muzzarelli, Cell Mol. Life Sci. 53, 131 (1997).

14. D. Koga, in: R. Chen, H. C. Chen (Eds.), Chitin enzymology-chitinase, Adv. Chitin Sci. 3, 16 (1998)

15. W. Ye, M.F. Leung, J. Xin, T.L. Kwong, D.K.L. Lee, P. Li, Polymer 46, 10538 (2005).

16. E. L. Johnson, Q.P. Peniston, Utilization of shell fish waste for chitin, chitosan, in R.E. Martin, G. J. Flick, C.E. Hebard, D.R. Ward, (Ed.) Chemistry and Biochemistry of Marine Food Products, AVI Publishing Co, Westport, CT. USA (1982).

17. R. A. A. Muzzarelli, German Offen 2923802 (1979).

18. F. Nicolaysen, Naturen, 273 (1980).

19. R. A. A. Muzzarelli, Ital. J. Biochem. 30, 167 (1981).

20. R. Muzzarelli, Chitosan, in: R. Muzzarelli (Ed.), Natural Chelating Polymers, Pergamon Press, Oxford, pp. 144-176 (1973).

21. H. Braconnot, Ann. Chim. Phys. 79, 265 (1811).

22. M. N. Kumar, R. A. Muzzarelli, C. Muzzarelli, H. Sashiwa, A.J. Domb, Chem. Rev. 104, 6017 (2004).

23. S. Hirano, Biotechnol Annu. Rev. 2, 237 (1996).

24. S. Patashnik, L. Rabinovich, G. Golomb, J. Drug Target 4, 371 (1997).

25. J. S. Song, C. H. Such, Y. B. Park, S. H. Lee, N. C. Yoo, J. D. Lee, K. H. Kim, S. K. Lee, Eur. J. Nucl. Med. 28, 489 (2001).

26. M. Ito, A. Ban, M. Ishihara, Jpn. J. Pharmacol. 82, 218 (2000).

27. V. R. Sinha, A. K. Singl, S. Wadhawan, R. Kaushik, R. Kumria, K. Bansal, S. Dhawan, Inter. J. Pharma. 274, 1 (2004).

28. J. Berger, M. Reist, J. M. Mayer, O. Felt, R. Gurny, Eur. J. Pharma. Biopharma. 57, 35 (2004).

29. H. Ueno, T. Mori, T. Fujinaga, Adv. Drug Deliv. Rev. 52, 105 (2001).

30. O. Felt, A. Carrel, P. Baehni, P. Buri, R. Gurny, J. Ocul. Pharmacol. Ther. 16, 261 (2000).

31. X.F. Liu, Y.L. Guan, D.Z. Yang, Z. Li, K.D. Yao, J. Appl. Polym. Sci. 79, 1324 (2001). 
32. S. Demarger-Andre, A. Domard, New properties of chitosan in lipid dispersions. In: Chitin World, Z.S. Karnicki, A. Wojtaso Pajak, M.M. Breziski, P.J. Bylowski, (Eds.), Bremerhauser, Germany, pp. 153-158 (1994).

33. L. Chen, D. Chen, C. Wu, J. Polym. Env. 11, 89 (2003).

34. R.W. Coughlin, M.R. Deshaies, E.M. Davis, Environ. Prog. 9, 35 (1990).

35. D. Durand, les réseaux macromoléculaires et les gels, groupe Français des polymères, chap. 5 (1990).

36. B. Guo, A. Elgsaeter, B.T. Stokke, Polymer Gels and Networks 6, 113 (1998).

37. A. Leonard, S. Blacher, M. Crine, W. Jomaa, Journal of Non-Crystalline Solids 354, 831 (2008).

38. G. Qun, W. Ajun, Z. Yong, J. Appl. Polym. Sci. 104, 2720 (2007).

39. C. K. S. Pillai, W. Paul, Chandra P. Sharma, Progress in Polymer Science 34, 641 (2009).

40. M. F. Cervera, J. Heinamaki, M. Rasanen, S. L. Maunu, M. Karjalainen, Carbohydr. Polym. 58, 401 (2004). 